\title{
Complex for experimental studies of anti-lock braking system operation
}

\author{
A S Potapov \\ Irkutsk National Research Technical University \\ Irkutsk, 664074, Russia \\ E-mail: batoha32303@rambler.ru \\ T A Tarasova \\ Irkutsk National Research Technical University \\ Irkutsk, 664074, Russia \\ E-mail: miss.gnom2011@yandex.ru
}

\author{
O A Svirbutovich \\ Irkutsk National Research Technical University \\ Irkutsk, 664074, Russia
}

M Y Fedyaev

Irkutsk National Research Technical University

Irkutsk, 664074, Russia

\begin{abstract}
Safety in automotive engineering depends very much on the brake system and its availability for use. That ability is usually tested on stands having cylindrical drums or on stands in the form of flat plates. Functionality of the brake system means not only slowing down a vehicle, but requires achieving a desired result such as stopping a vehicle at a given speed at a desirable distance There are some reports stating discrepancy of brake force measurement. The complex is designed to determine relations of automobile ABS operations The article describes a complex for experimental studies of antilock braking system (ABS) operation. The complex can be used to visualize braking and brake releasing processes for elastic-tired wheels during ABS operation.
\end{abstract}

Keywords-antilock braking system (ABS);braking moment; braking response; wheel speed

\section{INTRODUCTION}

Modern automobiles are equipped with antilock braking systems controlling wheel skidding when decreasing its speed and at a standstill.

An experienced driver can brake effectively without the use of ABS by means of controlling the moment of failure of the wheels on their own and weakening the braking force on the verge of blocking. The effectiveness of such braking can be compared with braking when using single-channel ABS. Multichannel systems in any case have the advantage in controlling the braking force on each individual wheel. The thing gives not only an effective deceleration, but also the stability of the vehicle behavior in difficult conditions of uneven adhesion of the wheels to the road surface.

The functioning of ABS when braking a wheel can be investigated with the help of a complex for experimental study of the processes of anti-lock braking systems operations.

Currently, the control of brake systems of motor vehicles is performed under operational conditions as well as in the road and in the test bed conditions (testing stand). Under the conditions of the Russian climate the most effective method of brake system control is said to be stand methods.

To study ABS operation, a group of researchers of Irkutsk National Research Technical University developed a research complex which can be used to analyze braking processes and

- vary the line speed of the roller;
- vary the normal wheel load;

- determine characteristics of longitudinal tire grip on the chassis-dyno roller surface;

- identify changes in line speed and chassis-dyno roller speed when braking;

- determine the braking torque when braking;

- control wheel braking [3].

\section{MATERIALS AND METHODS}

When the ABS system is triggered the processes of tyre interaction with the supporting surface are the most difficult from the standpoint of their study and formalization. Experimental studies of the output characteristics are carried out both in laboratory and in road conditions. The best quality experimental characteristics of ABS operation processes are typically received in the laboratory with the use of the complex for experimental studies.

The research and development complex shown in Figures 2 and 3 consists of chassis-dyno roller 1, driving system 2-6, ABS operation study system 9-19.

Chassis-dyno roller 1 is covered with asphalt concrete. Its external diameter is $1770 \mathrm{~mm}$. The roller rotates electrohydraulic gear 7 . It controls the rotation speed of the chassis dyno roller within the range of 0 to $22,6 \mathrm{rad} / \mathrm{sec}$. The line speed of the roller surface can be $20 \mathrm{~m} / \mathrm{sec}$. [2]

Asynchronous motor 2 with $\mathrm{N}=55 \mathrm{KW}$ rotates the chassis-dyno roller. Power is transferred from the motor to the roller through friction plate clutch 3 , step-by-step gear box 3 and chain gearing 6 [3]

The system for studying ABS operation consists of a mechanism for loading a wheel with normal loads $\mathrm{R}_{\mathrm{Z}}$, a mechanism for loading with braking torque $\mathrm{M}_{\mathrm{T}}$, aand a system for measuring longitudinal responses $\mathrm{R}_{\mathrm{Z}}$, of braking moment $\mathrm{M}_{\mathrm{T}}$, and angular speeds of the wheel a $\omega \kappa$ and the roller $\omega_{\sigma}$ (Fig. 2).

The mechanism for loading a wheel with normal loads consists of loading hydraulic cylinder 9 , double-arm level 10 , 
support 11, push frame 12 and compression spring 13. When generating liquid pressure in the hydraulic cylinder, its rod moves the lower end of double-arm lever 10. The upper end of lever 10 deforms spring 13 which loads wheel 14 through frame 12 with a normal load $\mathrm{R}_{\mathrm{Z}}$. The normal wheel load variation range is $0-8000 \mathrm{~N}$.

The loading hydraulic cylinders are controlled from the hydro station, the scheme of which is shown in Fig. 1. The tank 7 contains the working hydro-liquid. The fluid pressure in the hydraulic system creates a hydraulic pump 5 driven by an electric motor 6 . The operator controls the loading hydraulic cylinders of 1 and 8 , the dynamometers by switching the control valve 2 and 3 . In the case of increasing the hydraulic fluid pressure in the system, the protective function is performed by a safety valve 4 , which dissipates the overpressure from the high pressure line to the tank 7 .

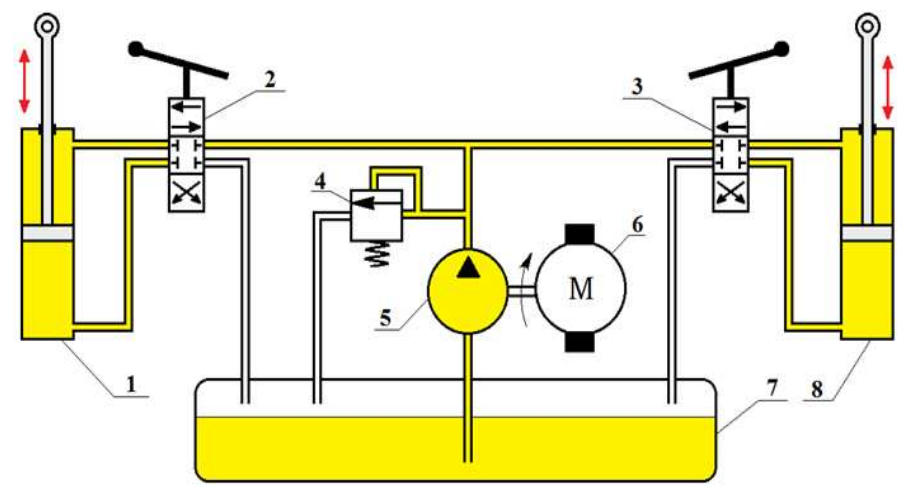

Fig. 1. A hydraulic control scheme of the loading hydraulic cylinders of the dynamometer.

1 - hydraulic cylinder of the loading wheel operating in the brake mode; 2 - valve controlling the operation of the hydraulic cylinder $1 ; 3$ - valve controlling the operation of the hydraulic cylinder $8 ; 4$ - protection valve; 5 - hydraulic pump; 6 - electric motor; 7 - a container with hydraulic fluid; 8 hydraulic cylinder of loading wheel moving with a skid.

The value of the normal response $\mathrm{R}_{\mathrm{Z}}$ is controlled by deformations of compression spring 13. Frame 12 and wheel 14 are positioned by support 11 and wheel suspension frame 15 which is fastened to tensile beam 16 (a device used for measuring braking responses $\mathrm{R}_{\mathrm{X}}$ ) with a movable joint.

Tensile beam 16 is a primary transducer of the system measuring longitudinal responses $R_{X}$. When the braking force directed along the axis of frame 15 occurs in the area of contact of the tire and the roller surface, response $R_{X}$ aiming to load the tensile beam with a bending moment occurs in the point where frame 15 is fastened to the tensile beam. Sensitive tensile sensors on the beam transform response $\mathrm{R}_{\mathrm{X}}$, into the changing resistance.

Mechanism 14 loading a wheel with a braking torque consists of roller-type brake 17 as a part of the ABS attached to the wheel by drive line 18 . Tensile sensors measuring a braking torque are mounted on drive line 18. To supply the tensile bridge and record tensile sensor signals, string-type current collector 19 is mounted in shaft 18. Along with the current collector, tensile sensors are elements of the system measuring the braking torque $\mathrm{M}_{\mathrm{T}}$. [2]

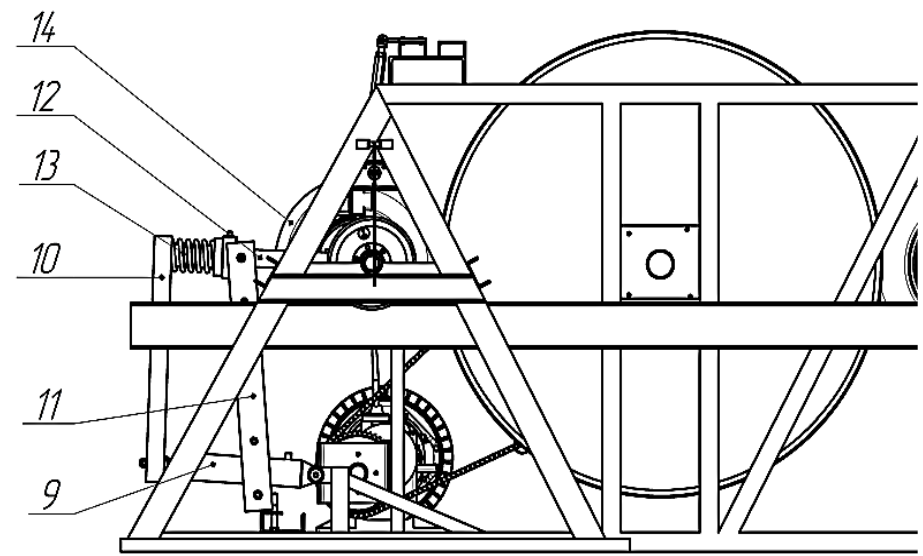

Fig. 2. A diagram of the system for studying ABS operation (plane view)

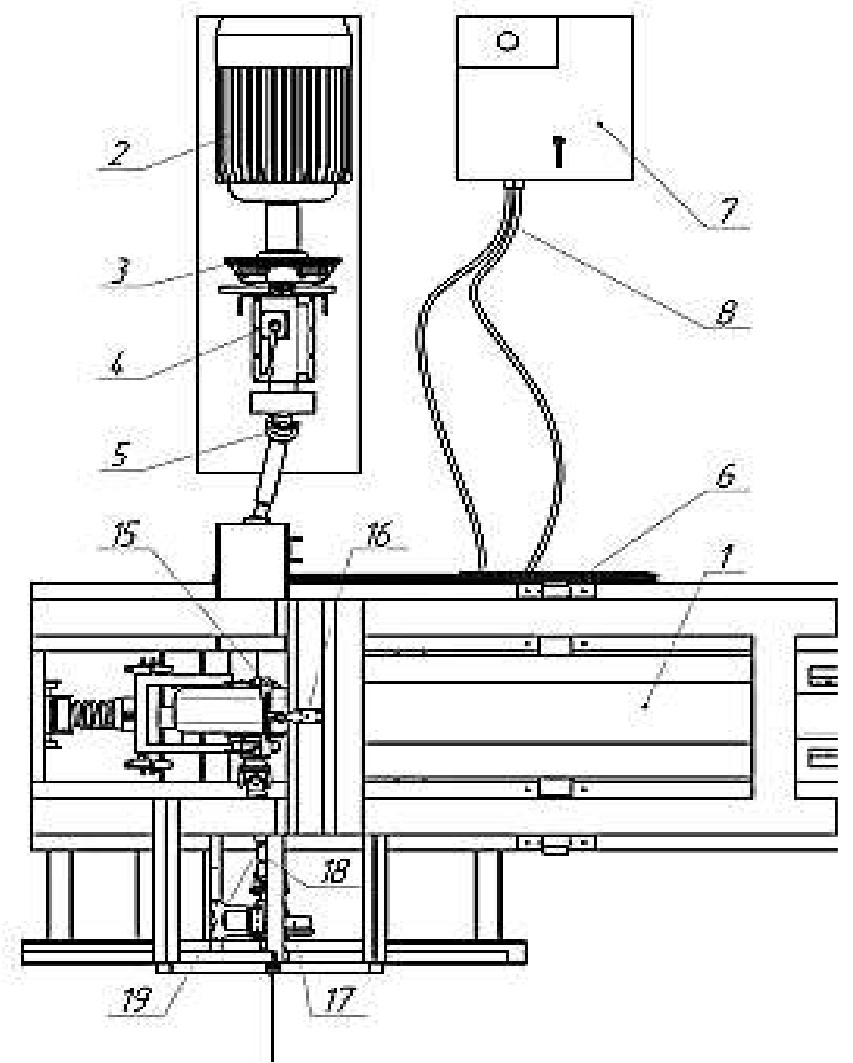

Fig. 3. A diagram of the system for studying ABS operation (front view)

The system studying ABS operations helps to identify experimental characteristics in the form of relations $R_{x}=f(t)$, $\mathrm{M}_{\mathrm{T}}=\mathrm{f}(\mathrm{t}), \mathrm{R}_{\mathrm{z}}=\mathrm{f}(\mathrm{t}), \mathrm{V}_{\mathrm{b}}=\mathrm{f}(\mathrm{t}), \mathrm{V}_{\mathrm{k}}=\mathrm{f}(\mathrm{t})$. 
The ABS is controlled from the hydraulic drive (it is not shown in Fig. 1 and 2). The drive consists of a main braking cylinder with a level and connecting lines. The brake loads a tested wheel with a braking torque in the range of 0 to 1,5 $\mathrm{kN} \cdot \mathrm{m}$. The ABS releases brakes when the skidding value $S_{\mathrm{cr}}$ is about 0,2 .

Figure 4 shows a general view of the dynamometer used for studying tire characteristics.

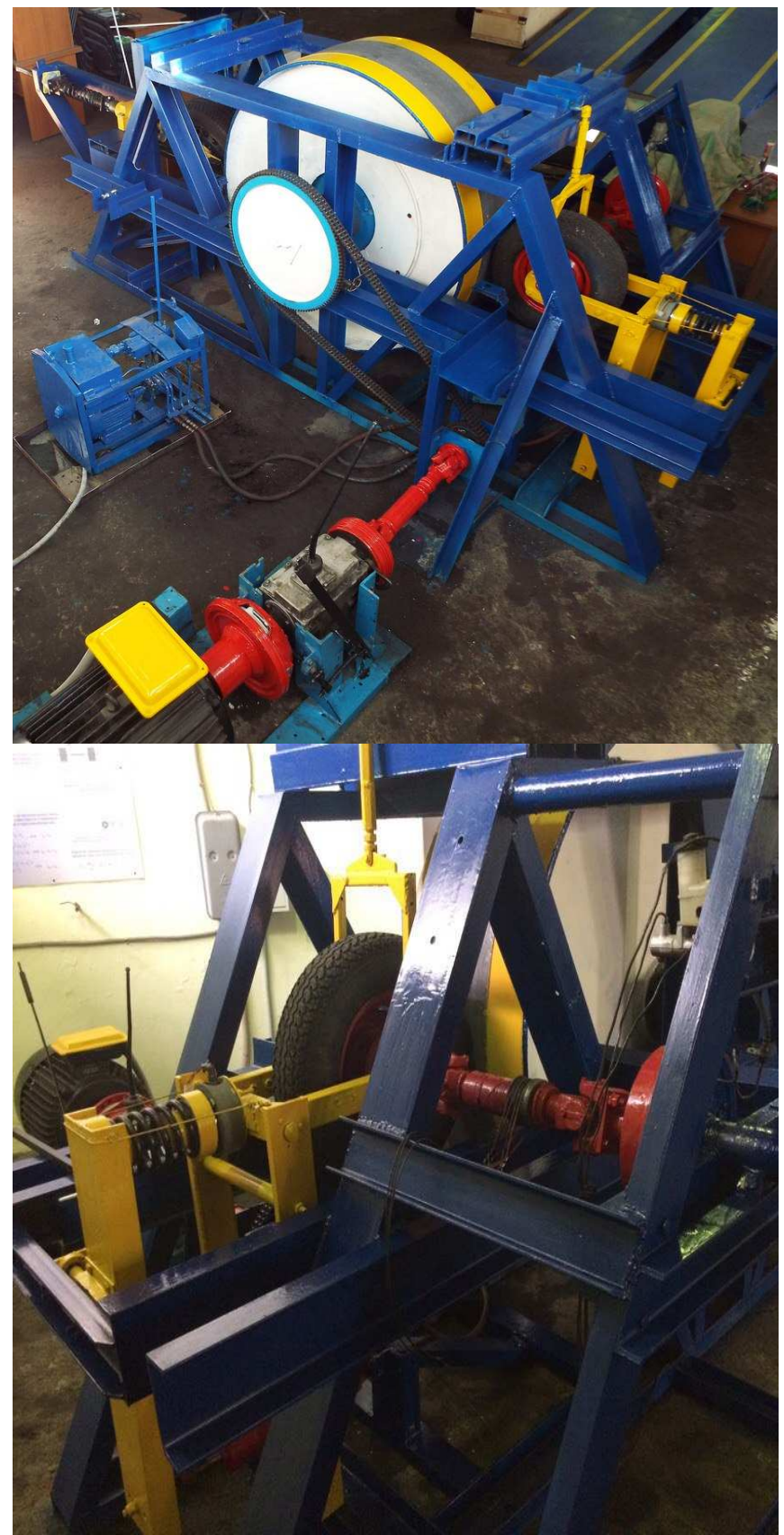

Fig. 4. A general view of the system studying ABS operation

To check the ABS operation when braking the wheel, it is necessary to obtain the diagrams of the normal $R_{\mathrm{Z}}$ and the longitudinal $\mathrm{R}_{\mathrm{X}}$ responses as well as the braking moment, wheel speed and speed of the chassis-dyno roller on time.
In order to get it, an experimental method was developed. It is based on the comparison of the results of measurement of normal load, longitudinal load, braking moment in the braking mode with the ABS operation.

To obtain the value of the normal load, the DST 9035 strain gauge sensor was used, designed to convert the measured force into an analog normalized electric signal.

To obtain the value of the longitudinal reaction, a strain transducer was used.

In the process of measuring the brake moment, it is necessary to measure the rolling moment $\mathrm{Mr}$ acting on the shaft. Strain gauge sensors were used for measurement.

Inductance transducers were used to measure the angular velocity of the wheel and the chassis dynamometer.

The sensor signals were passed through an ADC and processed with the help of ZETLab programs.

The experiment was carried out during braking after reaching the speed of the wheel $45 \mathrm{~km} / \mathrm{h}$.

The experiment involves the following steps:

- to connect measuring sensors to operational amplifiers;

- to switch an ADC with a connected computer;

- to connect the amplifier to the ADC using an adapter loop;

- to switch on the measuring system;

- to switch on the dynamometer and warm up dynamometer systems;

- to check tire pressure and bring it to a required value;

- to create a normal wheel load using a hydraulic cylinder;

- to switch on the computer signal record and build loading diagrams in Zetlab;

- to run an electric motor and a roller;

- to switch off the electric motor and press the brake gear lever;

- to measure the normal load, braking force and braking torque in the braking mode;

- to unload the wheel using a hydraulic cylinder;

- to deenergize the dynamometer;

- to save sensor's values;

- to deenergize the operational amplifier and disconnect the loop from the ADC;

- to analyze the data obtained.

\section{RESULTS AND DISCUSSION}

Key ABS operation parameters in the braking mode are the relationship between normal $R_{\mathrm{Z}}$ and longitudinal $\mathrm{R}_{\mathrm{X}}$ responses, braking torque, wheel speed and roller speed and time. 
All these parameters were identified experimentally and are shown in Fig. 5.

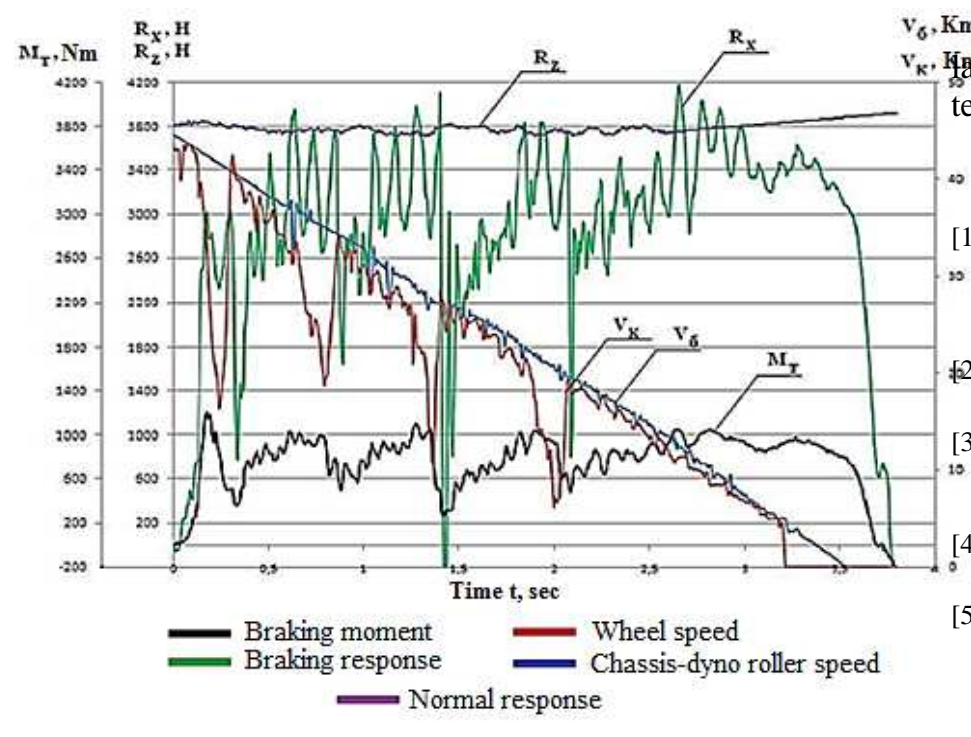

Fig. 5. An oscillogram of the relationship between braking torque, braking response, wheel and roller speed, normal response and time

\section{CONCLUSIONS}

The graphs of the change in brake moment, brake response, normal response, wheel speed, speed of the chassisdyno roller were obtained due to the results of the experiment carried out on the complex for experimental studies of antilock braking system operation.

1. Anti-lock systems are widely used in the design of modern brake systems of vehicles. The manufacturing of the vehicles equipped with anti-lock systems is growing steadily from year to year.

2. The experiments using a laboratory system for experimental studies of ABS operation visualize the elastictired wheel brake releasing process in the braking mode.

3. The parameters identified using the developed system can be used for assessing adequacy of mathematical braking models for automobile wheels as a part of the ABS.

4. The system for the experimental study of ABS operation when braking the automobile wheel on the dynamometer with the chassis dynamometer will be used for laboratory work in which dependency diagrams of the braking torque, braking response, wheel speed, roller speed, the normal response of the braking time will be obtained to demonstrate ABS operation..

$v_{6}, \mathrm{Km} / \mathrm{h}$ The results can be used for educational purposes, $v_{k}$. Tigabbratory works when training professionals in transport and technological machines and systems engineering.

\section{References}

1] A.I. Fedotov. "Studies of the elastic-tired wheel braking process under variable normal loading",. pp. 167-178, April 2017, Vehicle safety under operation conditions. Proceedings of the 99th International Scientific and Engineering Conference, p. 478, 2017.

\$2] A.I. Fedotov "The dynamometer for studying tire properties", Journal of automobile engineers, vol. 1, pp. 30-33, 2015.

3] A.I Fedotov, N.Y. Kuznetsov "Tire tester with chassis-dyno rollers for studying tire properties", Bulletin of Irkutsk State Technical University, vol. 2, pp. 123-126, 2016.

4] A.I. Fedotov "Diagnosis of a pneumatic brake drive vehicles on the basis of computer technology", Dr. Sc. Engineering: 05.20.03, Irkutsk, 1999.

[5] A. I. Fedotov, Car diagnostics: a textbook for University students enrolled in the direction of training of bachelors and masters "Exploitation of transport and technological machines and systems", Ministry of education and science of the Russian Federation, Irkutsk state technical University Irkutsk, 2012.

[6] A. I. Fedotov, "Fundamentals of scientific research: teaching manual", Publishing house of ISTU, Irkutsk, 2012.

[7] A. I Fedotov "Pilot studies of elastic wheel interaction with chassis dynamometer and road", Proceedings of Irkutsk state technical universit,vol. 9 (68), pp. 157-163, 2012.

[8] A. I. Fedotov "The experimental study of the parameters characteristic of interaction of an automobile wheel with the bearing rollers of diagnostic stands," Proceedings of Irkutsk State Technical University,vol. 4 (40), pp. 72-77, 2009.

[9] B. C Gerner, Study of modes of control of the effectiveness of braking mechanisms: Diss.... PhD in Engineering, Kharkov, 1970.

[10] V. E. Jutt, Operation of anti-lock systems of cars: a textbook, 2003.

[11] M. A. Petrov, Operation of wheels in braking mode, Omsk, Zap. Sib. book. ed. 1973.

[12] A. I. Fedotov, A. B. Dick "Rolling brake wheel loaded with variable normal load", Proceedings of "Active and passive safety and reliability of the car, pp. 94-110, 1984.

[13] A.I Fedotov, A.V Boiko "Effectiveness of control methods bench brake systems in operation" pp. 115-125, Proceedings. II International Scientific and Practical Conference "Problems of diagnosis and operation of road transport, p 345, 2009].

[14] A.I. Fedotov, A.V. Boiko, D. Tsogt "Experimental study of the parameters characterizing the interaction of road wheels or castors diagnostic stands", ISTU Herald, vol. 4, pp. 72-77, 2009.

[15] A.I. Fedotov, A.V. Boiko, D. Tsogt, et al. Experimental studies of the interaction of elastic wheel racing drums and expensive., pp. 157-163, ISTU Herald. no. 9. - Irkutsk: Irkutsk State Technical University, p 230,2012 . 